\title{
REMOVAL OF CRYSTAL VIOLATE DYE FROM AQUEOUS SOLUTION BY ADSORPTION ON MIXTURE OF ACTIVATED CARBON: A KINETIC \& EQUILIBRIUM STUDY
}

\author{
P.B.wagh ${ }^{1}$ and V.S.Shrivastava ${ }^{2}$ \\ ${ }^{1}$ North Maharashtra university Jalgaon,Maharashtra, \\ ${ }^{1}$ Department of Chemistry J.E.S. . Arts, Science, and Commerce College, Nandurbar -425412(India). \\ Email:waghprakash2@gmail.com \\ ${ }^{2}$ Nano Chemistry Research Laboratory, G.T.P. College, Nandurbar -425412 (India) \\ North Maharashtra university Jalgaon,Maharashtra \\ Email: drvinod_srivastava@yahoo.com
}

\begin{abstract}
The kinetics and equilibrium study of crystal violate dye adsorption on mixture of activated carbon (PWCAC) and (CSAC) was studied. The use of low cost ecofriendly adsorbent has been investigated as an ideal alternative to the current expensive methods of removing of dye from aqueous solution. This study was done by batch adsorption techniques. The quantitative adsorption kinetic and equilibrium parameter for crystal violate dye were studied using us-visible adsorption spectroscopy. The effect of initial dye concentration, $\mathrm{pH}$, adsorbent dose, temperature, particle size were determined to find the optimal condition for adsorption. The percentage removal of dye was found to be most effective at $\mathrm{pH}_{10}$ and contact time $120 \mathrm{~min}$ and at an adsorbent dose $4 \mathrm{~g} / \mathrm{L}$ of dye. The study indicates that's, the percentage removal of dye increases with increasing initial dye concentration, adsorption dose and contact time and attains equilibrium at optimum conditions.

The equilibrium study of adsorption of crystal violate dye on to mixture of activated carbon was investigated using pseudo first order and pseudo second order kinetic models. The adsorption kinetics was found to follow pseudo second order kinetic model. The equilibrium adsorption data of crystal violate dye on PWCAC and CSAC mixture was analyzed by Langmuir and Freundlich adsorption model. The results show that the Langmuir model provides the best correlation.
\end{abstract}

Keywords: Crystal violates adsorption kinetics; equilibrium study; and activated carbon mixture; FTIR; EDAX and SEM.

\section{Council for Innovative Research}

Peer Review Research Publishing System

\section{Journal: Journal of Advances in Chemistry}

Vol. 11, No. 9

www.cirjac.com

editorjaconline@gmail.com, editor@cirjac.com 


\section{INTRODUCTION}

The discharge of highly colored dyes effluents from dyes industries can disturb the aquatic life by decreasing sunlight penetration or by direct poisoning of living organism [1]. This problem is created due to non-degradable nature of synthetic dyes by chemical or photochemical process [2]. So for this the alternative procedure must be employed for the elimination of such a dyes before disposal. In this field the study and development of adsorption technique is very interesting approach. Different materials have been applied for the adsorption of different basic dyes from aqueous solution. The treatment processes like photo catalytic degradation, integrated chemical biological degradation, adsorption on activated carbon have been used to remove dyes from the dye waste water effluents [3-5]. A synthetic dye in waste water cannot be effectively decolorized by traditional method [6].

The high cost of removal of dye from aqueous solution using adsorption on commercial activated carbon though very effective has motivated the search for the alternative adsorbent. The agricultural byproduct is considered to be low value product. Due to their low utilization and most of the biomaterial are set to fire or discarded. This process creates resources losses and environmental pollution. The utilization of this material must bring economic and social benefit to the mankind. Recently an attention has been focused on the utilization and characterization of this native agricultural byproducts [7-8].The activated carbon perhaps the most widely used adsorbent for the removal of many organic dyes. Activated carbons exhibit an extended surface area, highly developed pore structure (in particular, microspores) and a high surface reactivity (Bansal and Goyal, 2005), so they are generally used to remove hazardous dyes and heavy metals from aqueous solution. The present study is undertaken to evaluate the efficiency of a mixture of activated carbon prepared from palm wood cellulose activated carbon (PWCAC) and coconut shell activated carbon(CSAC)[9]. The adsorption study was carried out involving various parameters as initial concentration, adsorbent dosage, agitation time and $\mathrm{pH}$. The kinetics of the adsorption process and the thermodynamic parameters governing the adsorption process were evaluated and discussed. The data has been tabulated and discussed in the view of the above; the mixture is used in a definite proportion for the removal of basic dye (Crystal violet) from an aqueous solution.

\section{MATERIALS AND METHOD}

\subsection{Preparation of adsorbent}

The precursor material was collected from the local sources. The material was converted into small pieces and then washed several time by distilled water and then put in sunlight to dry for 24 hours. The small pieces are converted into different sized particles by grinding in ball mill. The material was sieved to an average particle size. The obtained material was activated chemically. A $50 \%$ zinc chloride solution was used for activation. The material was soaked in $\mathrm{ZnCl}_{2}$ solution for 24hours. Then after decantation, the sample was pyrolyzed in Muffle Furnas in absence of air at $600^{\circ}$ for 60 min. The obtained material is used as an adsorbent [10]. The material is further used without purification as an adsorbent.

\subsection{Adsorbate}

The basic dye, crystal violate (C.I.42555) is colored water soluble powder. The crystal violate has molecular formula $\mathrm{C}_{25} \mathrm{H}_{30} \mathrm{~N}_{3} \mathrm{C}$ and molecular weight $408 \mathrm{gm}^{-1}$ and wave length $590 \mathrm{~nm}$ was used as adsorbate. It is supplied by SD fine chemicals Mumbai. The crystal violate has structure [11].

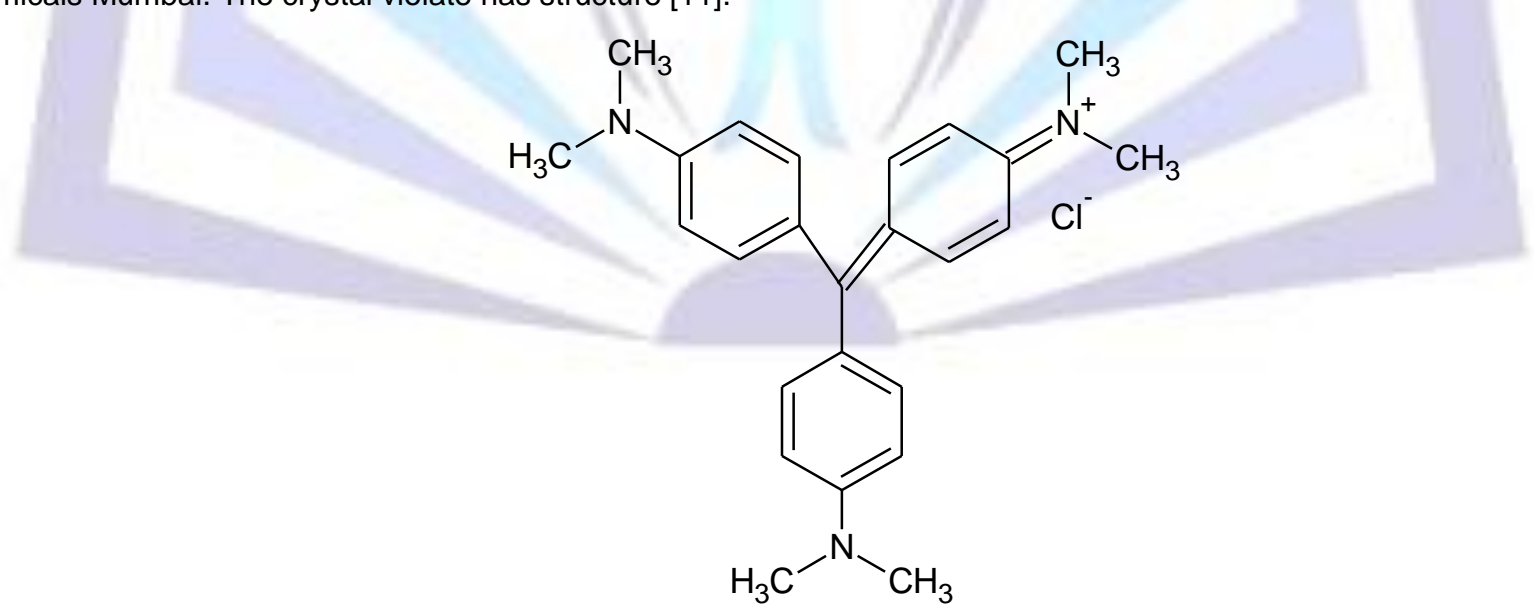

Fig.1: Structure of crystal violate

1000 ppm stock solution of crystal violate dye was prepared by dissolving $1 \mathrm{gm}$ of dye in double distilled water and from that stock solution a required ppm solutions were prepared for the experimental study.

\section{RESULT AND DISCUSSION}

The adsorption experiments were carried in a batch process at room temperature by using an aqueous solution of crystal violates dye. In each experiment an accurately weighed amount of PWCAC and CSAC mixture was added in 50ml of the dye solution in $100 \mathrm{ml}$ stopperd conical flask and then mixture was agitated in the mechanical shaker for a definite time at a 
room temperature. The adsorbent was separated from the solution by centrifugation. The absorbance of the supernant solution was estimated to determine the residual dye concentration. The residual dye concentration was determine before and after treatment at 590nm wave length with spectrophotometer (Systronics -118) using quartz's cell of path length $1 \mathrm{~cm}$. The experiment were carried out at initial $\mathrm{pH}$ values ranging from 2 to $10 \mathrm{pH}$. The removal of dye from 2 to $10 \mathrm{pH}$ were measured by using $\mathrm{pH}$ meter (Equiptronics model EQ 607). The initial $\mathrm{pH}$ was controlled by addition of $0.1 \mathrm{NHCl}$ and $0.1 \mathrm{NaOH}$ solution. The kinetic of adsorption was determined by analyzing adsorptive uptake of dye from aqueous solution at different time intervals. The FTIR, SEM, XRD) of adsorbent was also carried

\subsection{Adsorbent characterization}

\subsubsection{FTIR}

The FTIR of mixed carbon fig (1) showed that the presence of peaks for a large number of functional groups. Viz $3432 \mathrm{~cm}-{ }^{1}$ is due to $\mathrm{O}-\mathrm{H}$ stretching frequency in alcohol or it may be due to $-\mathrm{N}-\mathrm{H}$ stretching frequency in amines $.2852 \mathrm{~cm}^{-}{ }^{1} \mathrm{and} 2926 \mathrm{~cm}-{ }^{1}$ is due to $-\mathrm{C}-\mathrm{H}$ stretching frequency $.1570-1630 \mathrm{~cm}^{-1}$ is due to aromatic $>\mathrm{C}=\mathrm{C}<$ stretching frequency $.1270,1315,1384 \mathrm{~cm}-{ }^{1}$ is due to C-N stretching frequency in amines $.1111 \mathrm{~cm}^{-1}$ is due to $-\mathrm{C}-\mathrm{O}$ stretching frequency $.780 \mathrm{~cm}-{ }^{1}$ is $\mathrm{C}-\mathrm{H}$ bending frequency in alkene or $\mathrm{C}-\mathrm{Cl}$ stretching frequency. The $471-577 \mathrm{~cm}-{ }^{1}$ is for $\mathrm{C}-\mathrm{Br}$ stretching frequency .

The FTIR of mixed carbon after the dye adsorption fig.(2) showed that the the presence of peaks for for the large no of functional groups. The $3407 \mathrm{~cm}^{-1}$ is due to stretching frequency in alcohols, phenol or $\mathrm{N}-\mathrm{H}$ stretching frequency in amines. The $2926-2852 \mathrm{~cm}^{-1}$ is due to $-\mathrm{C}-\mathrm{H}$ stretching frequency in alkanes.the $1581,1616,1413 \mathrm{~cm}-{ }^{1}$ may be due to aromatic $>\mathrm{C}=\mathrm{C}<$ stretching frequency.the $1382,1315 \mathrm{~cm}^{-1}$ is due to $>\mathrm{C}-\mathrm{N}$ stretching frequency in amines. $1174 \mathrm{~cm}^{-1}$ is due to $-\mathrm{C}-\mathrm{O}$ stretching frequency. $779 \mathrm{~cm}^{-}$is due to $-\mathrm{C}-\mathrm{H}$ bending frequency in in alkenes or $-\mathrm{C}-\mathrm{Cl}$ stretching frequency. $568,673 \mathrm{~cm}-{ }^{1}$ is for $\mathrm{C}-\mathrm{Br}$ stretching frequency. $1413 \mathrm{~cm}^{-1}$ is for $\mathrm{C}-\mathrm{H}$ bending frequency in alkane.1174.1350,1382 $\mathrm{cm}^{-}{ }^{1}$ is due to $\mathrm{S}=\mathrm{O}$ stretching frequency in sulfonic acid.

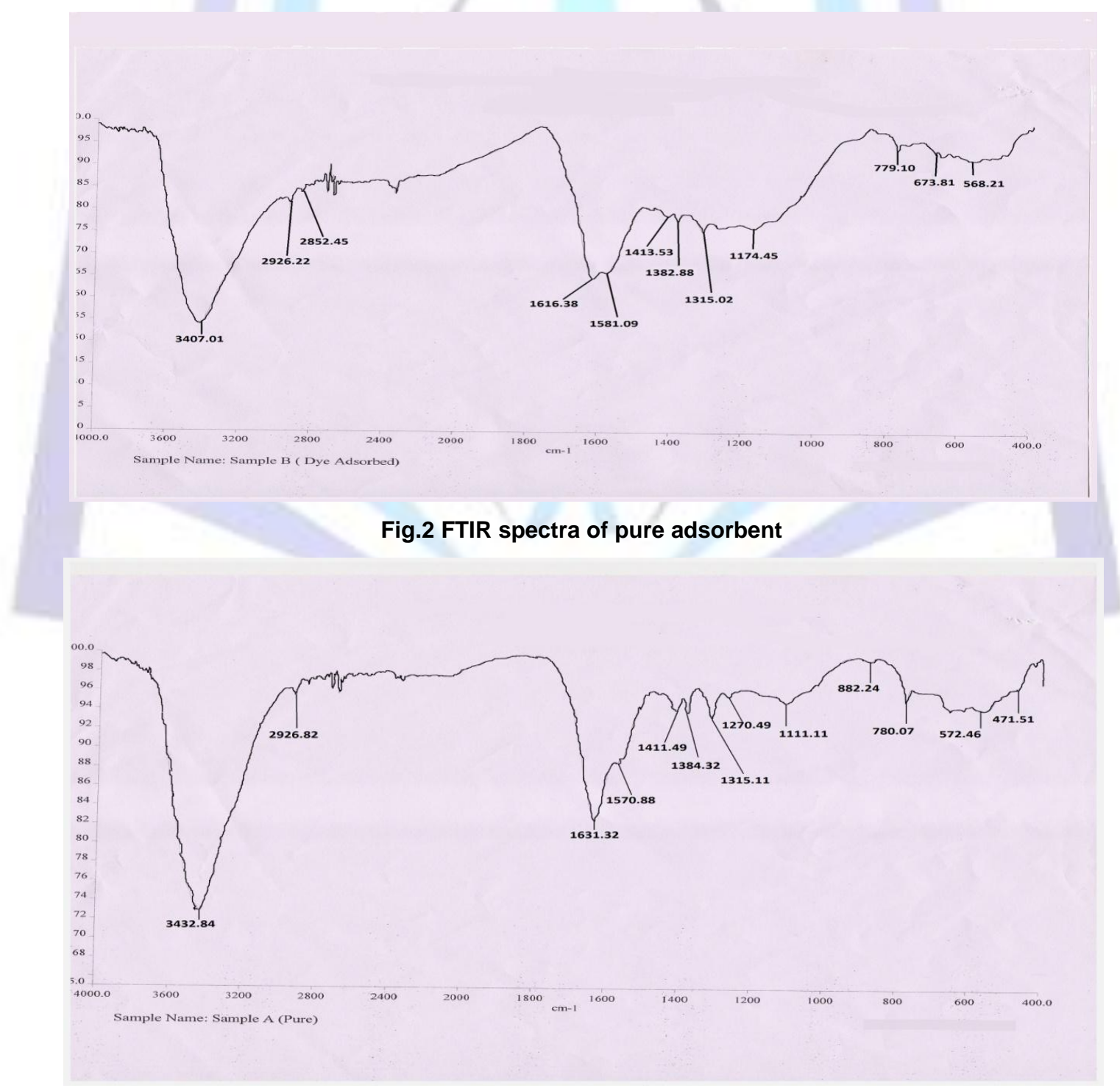

Fig.3 FTIR spectra of dye adsorbed adsorbent 


\section{ISSN 2321-807X}

\subsubsection{XRD Analysis}

The XRD diagram of mixture of PWCAC and CASC is shown in (fig 3) The XRD of mixed adsorbent shows main peak $2 \Theta$ of $24.44^{\circ}$ and $2 \Theta$ peak $26.73^{\circ}$ and $2 \Theta$ at $72.48^{\circ}$ respectively. The high intensity of peaks indicates the highly crystalline nature of PWCAC and CSAC carbon. The average particle size is estimated by Scherer formula. The size of particle observed is $7.1 \mathrm{~nm}, 18.44 \mathrm{~nm}$ and $16.7 \mathrm{~nm}$.

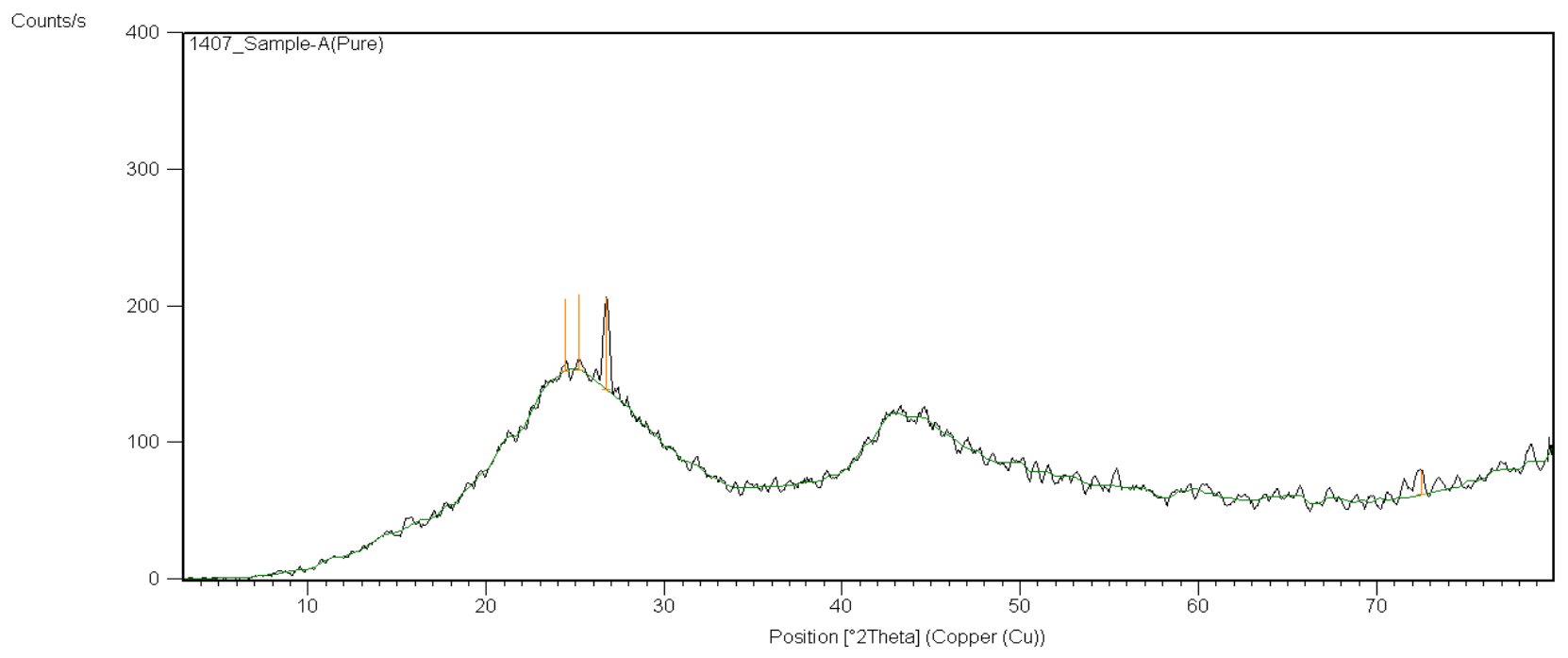

Fig.4 XRD Spectra of mixed adsorbent PWCAC and CSAC

\subsubsection{SEM Analysis}

The scanning electron microscope (SEM) is widely used to study the morphological features and surface characteristics of adsorbent material. It is useful to determine particle shape, porosity and appropriate size distribution of the adsorbent material.

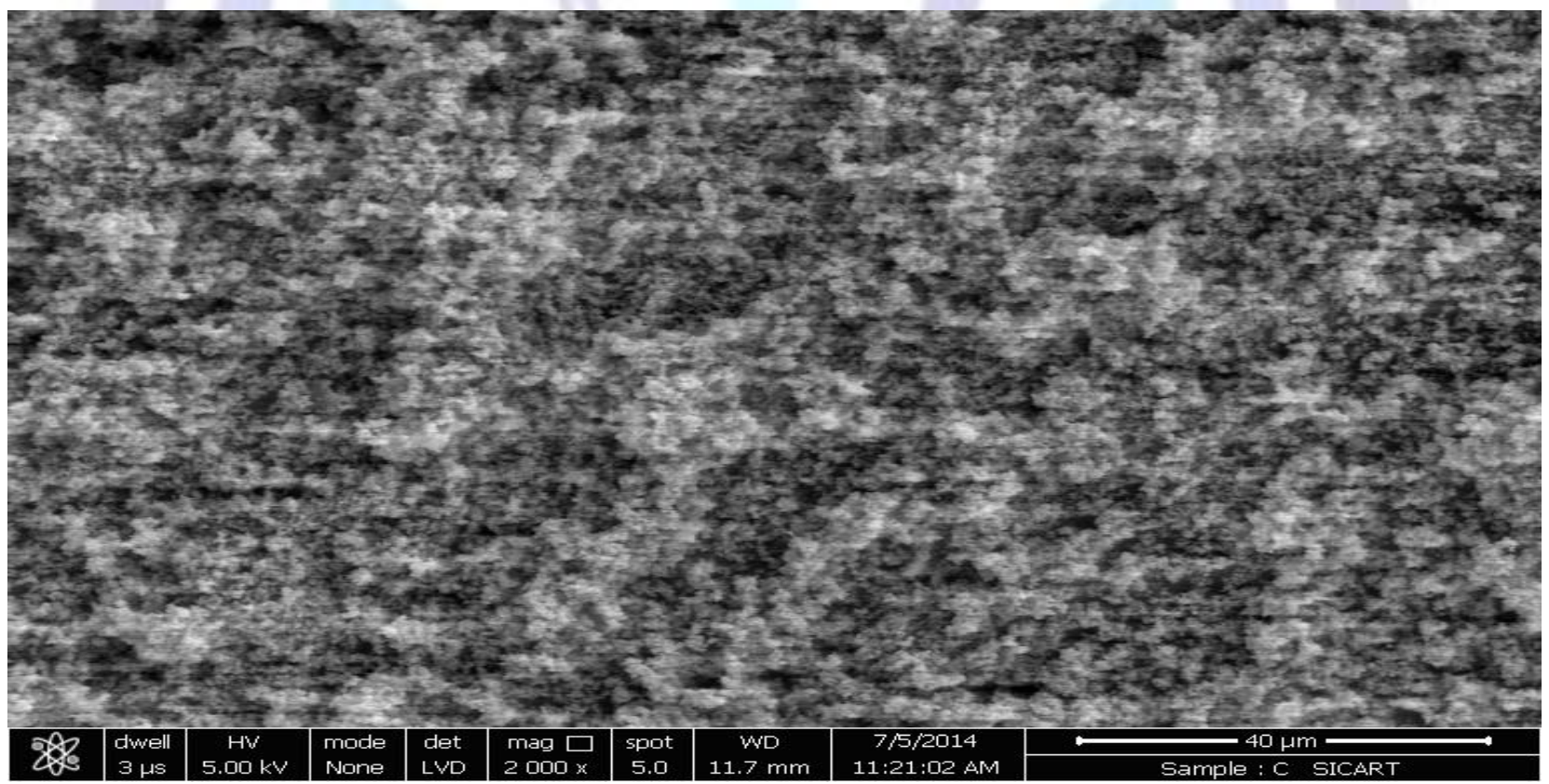

Fig.5 The SEM micrograph of PWCAC and CSAC of mixed carbon 


\section{ISSN 2321-807X}

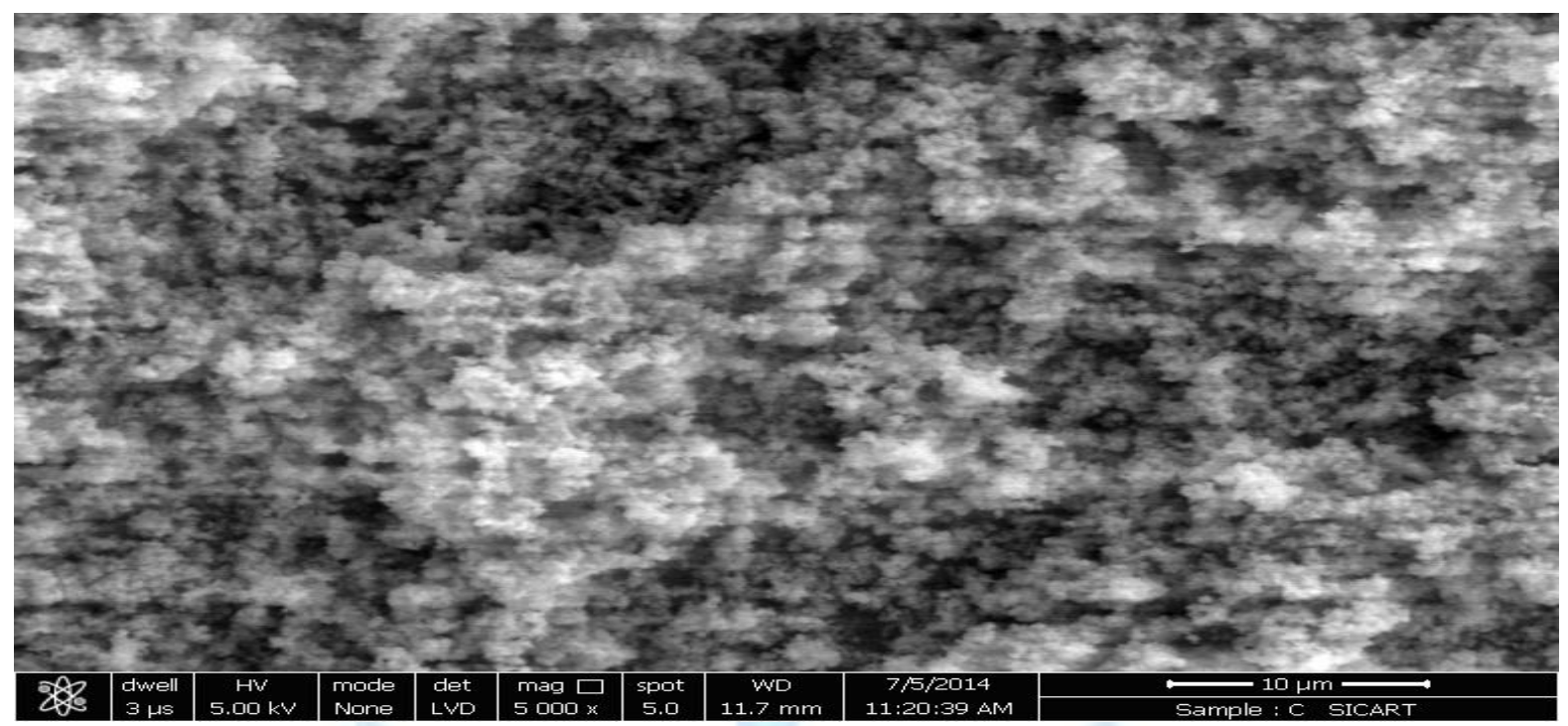

Fig.6 The SEM micrograph of PWCAC and CSAC mixed carbon after adsorption of dye

\subsubsection{EDAX}

It is energy dispersive $x$ ray spectroscopy and it is a chemical microanalysis techniques used in conjunctions with SEM.EDAX analysis was used to characterize the elemental composition of PWCA and CSAC.The EDAX of elemental analysis shows $28.51 \%$ of $\mathrm{C}, 21.8 \% \mathrm{H}$ before adsorption and $88.40 \% \mathrm{C}$ and $9.18 \% \mathrm{O}$. after adsorption.

\subsection{Effect of $\mathrm{pH}$}

The experiment were carry out at $60 \mathrm{mg}$ of initial dye concentration with $4 \mathrm{~g} / \mathrm{L}$ adsorbent dose for 120 min equilibriums time and in the range of $\mathrm{pH}$ change from 2 to 12 . Intialy when $\mathrm{pH}$ increases from 4 to 10 the percentage removal increases from $91.98 \%$ to $98.12 \%$ and it slightly decreases up to 91 . \% for $\mathrm{pH} 12$. The maximum percentage removal occurs at $\mathrm{pH}$ 10 and hence the $\mathrm{pH} 10$ is selected as a optimum $\mathrm{pH}$.

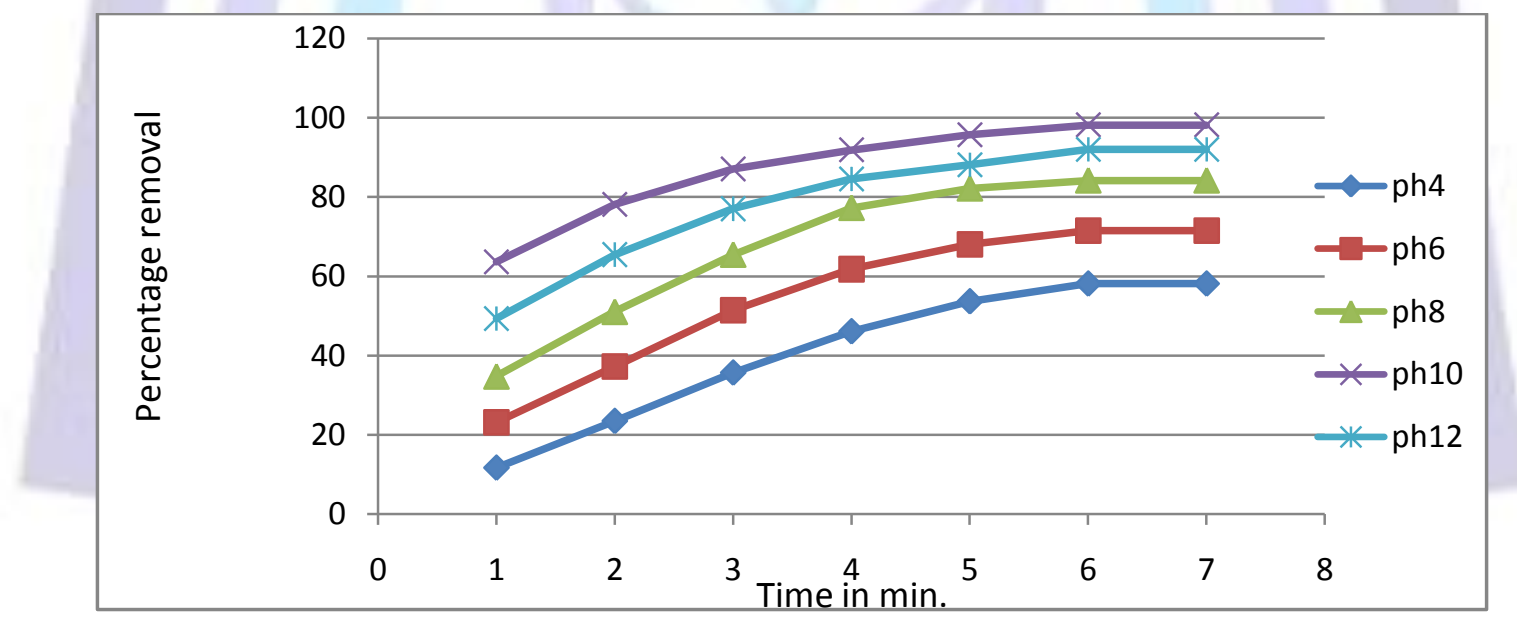

Fig.7: Effect of pH on percentage removal of crystal violate Dye at different $\mathrm{pH}$, initial dye concentration 60ppm, And adsorbent dose $4 \mathrm{~g} / \mathrm{L}$ at $\mathrm{pH} 10$, contact time $120 \mathrm{~min}$.

\subsubsection{Effect of contact time}

The amount of dye adsorbed qt (Mg/gm) increased with increasing in agitation time and reached to the equilibrium after $120 \mathrm{~min}$, for the dye concentration $20,30,40$, and $60 \mathrm{ppm} / \mathrm{L}$. Thus time required to achieve a definite fraction of equilibrium adsorption was found to be $120 \mathrm{~min}$ and it is independent of dye concentration. The adsorption density $\mathrm{qt}(\mathrm{mg} / \mathrm{gm})$ also increased with increasing dye concentration. The percentage of dye removal at equilibrium increases from $84.21 \%$ to $96.96 \%$ as dye concentration increased from 20 to $60 \mathrm{mg} / \mathrm{L}$ for $4 \mathrm{~g} / \mathrm{L}$ of adsorbent does at $\mathrm{pH} 10$. This shows that removal of crystal violate depends on concentration of dye. The maximum \% removal of dye occurs at $60 \mathrm{ppm}$ and hence it is selected for further study [12-14]. 


\section{ISSN 2321-807X}

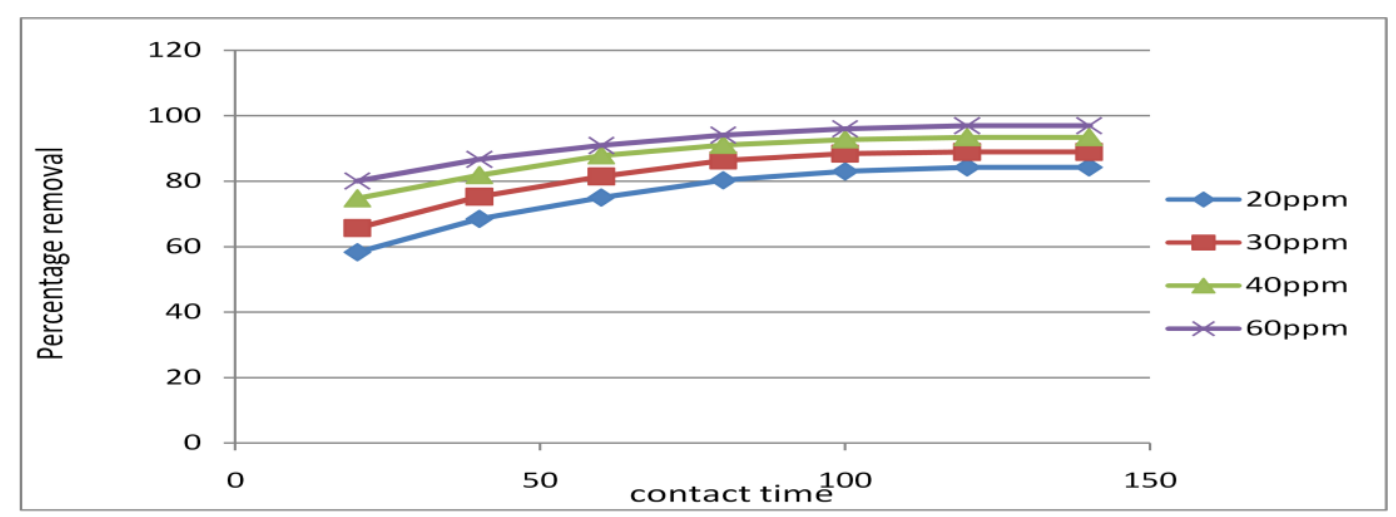

Fig.8: Effect of contact time and concentration of crystal violet on Percentage removal, adsorbent dose $4 \mathrm{~g} / \mathrm{L}$, PH10 and contact time $120 \mathrm{~min}$.

\subsection{Effect of adsorbent dose}

The effect of adsorbent dose on the amount of dye adsorbed was studied. The equilibrium value of amount of dye absorbed was observed to be increased from $81.17 \%$ to $97.19 \% \mathrm{mg} / \mathrm{L}$ with increase in adsorbent dose from $0.02 \mathrm{gm}$ to 4 $\mathrm{g} / \mathrm{L}$ for $60 \mathrm{mg} / \mathrm{L}$ dye concentration ,contact time $120 \mathrm{~min}$ and $\mathrm{pH} 10$.The percentage removal of crystal violate increased with increasing dose of adsorbent and that is due to the increased in availability of surface active sits resulting from increased of dose and agglomeration of adsorbent. The increase in the extent of removal of crystal violate is found to be significant at the dose $4 \mathrm{~g} / \mathrm{L}$ and hence it is fixed as a optimum dose for adsorbent [15] .

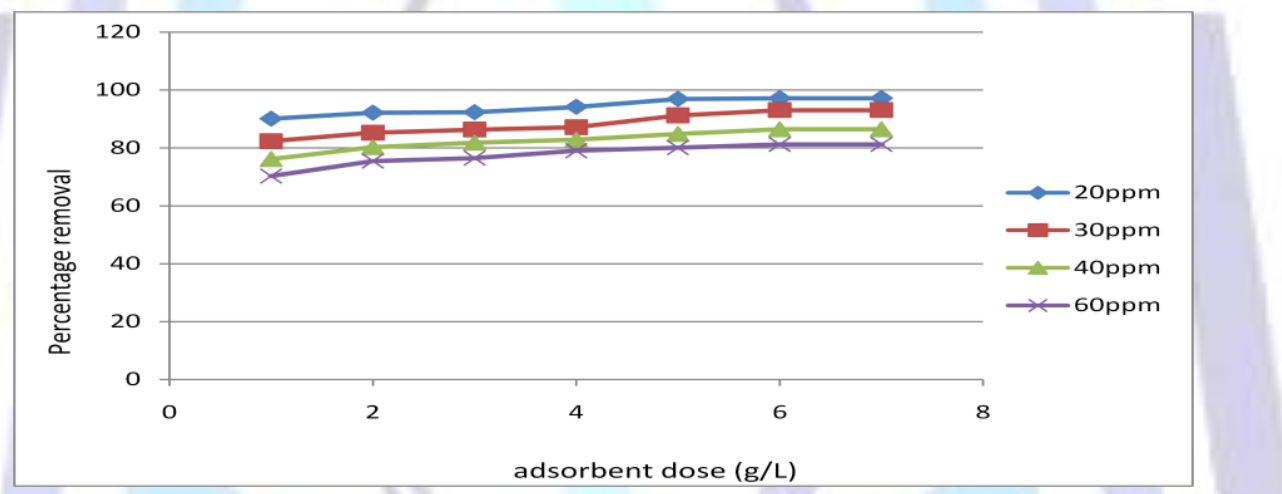

Fig. 9: Effect of adsorbent dose on percentage removal of crystal violet dye for initial dye concentration, Contact time 120min, pH 10.

\subsection{Effect of initial dye concentration}

The adsorbent and dye solution of different initial dye concentration $20 \mathrm{mg}$ to $200 \mathrm{mg} / \mathrm{L}$ was contacted for $120 \mathrm{~min}$ at $\mathrm{pH} 10$ and at a constant adsorbent dose $4 \mathrm{~g} / \mathrm{L}$. The result shows that the percentage removal of dye increases from $84.21 \%$ to95.96.96 \%-when initial dye concentration increases from 20 to $60 \mathrm{mg} / \mathrm{L}$ this shows that the crystal violate gets Removed by adsorption[15].

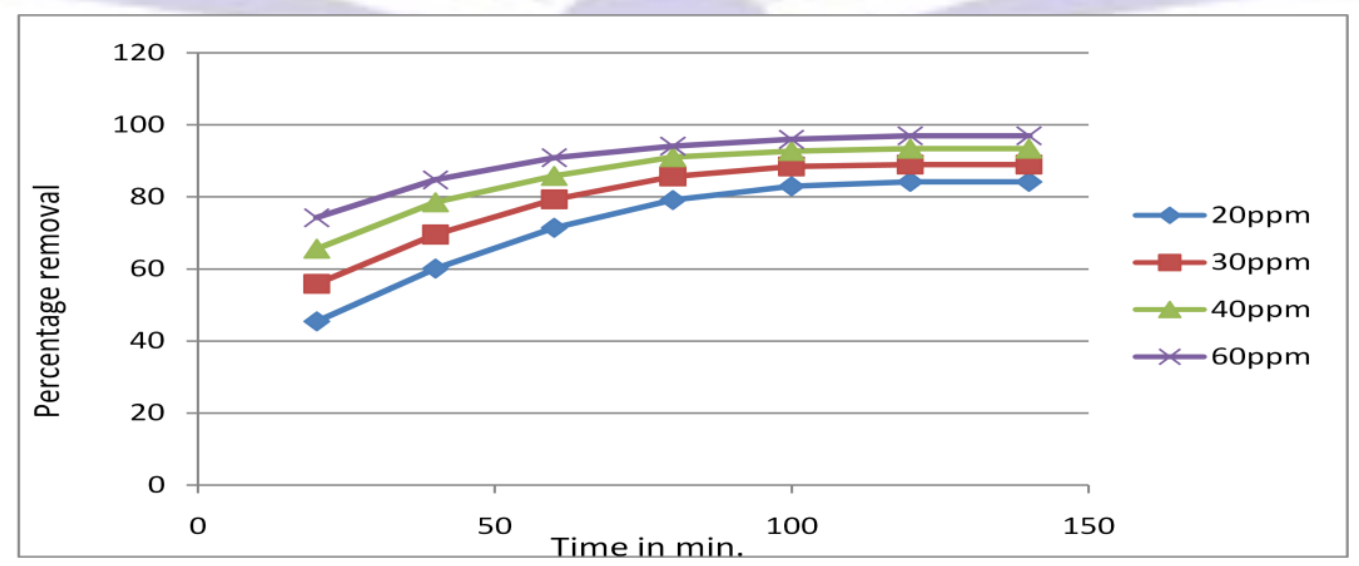

Fig.10: Effect of initial dye concentration on percentage removal Crystal violate by PWCAC and CSAC Mixture, Adsorbent dose $4 \mathrm{~g} / \mathrm{L}$ and $\mathrm{pH} 10$ 


\subsection{Effect of partical size}

The adsorption experiment was carried out by using different mesh size partical ranging from 50 to 250 mesh size. It is observed that the adsorption of dye decrease with increase of particle size and increase with decrease in particle size that

is due to large surface area availability. For $100 \mathrm{~nm}$ particle size the 5 removal is maximum and it is $89 . \% 47[16]$.

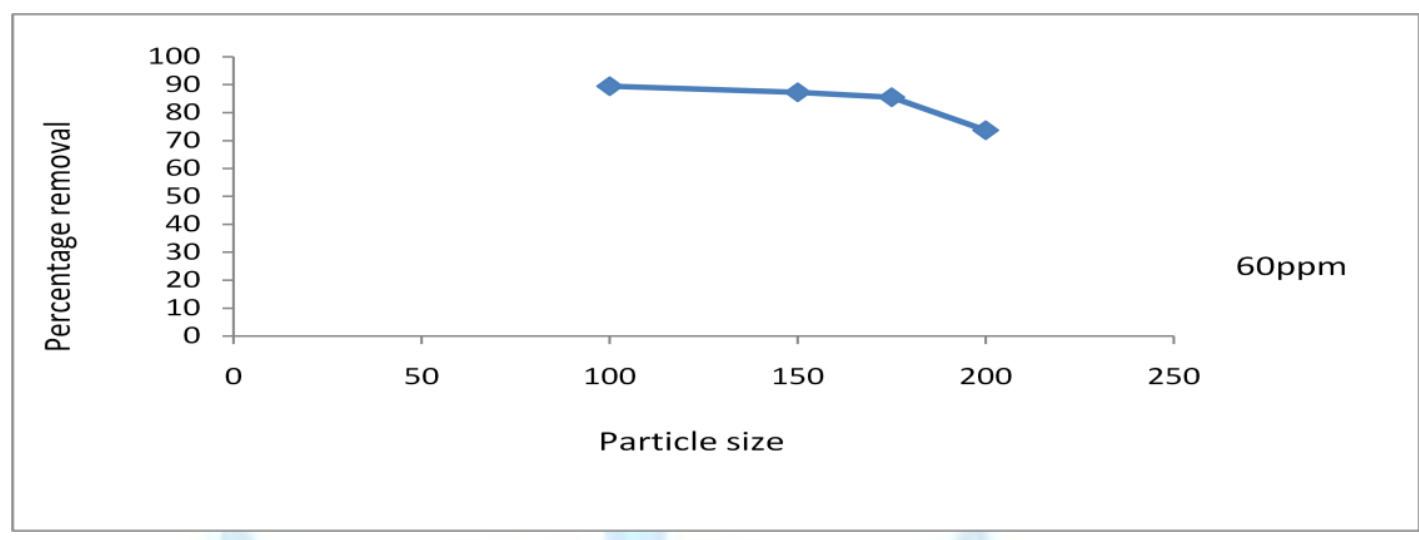

Fig.11: Effect of particle size on removal of crystal violate $(\mathrm{Co}=60 \mathrm{ppm})$ by PWCAC and CSAC.

\subsection{Effect of temperature}

The experiment was carried out at three different temperatures i.e. from 40,50 and $60^{\circ}$. It is observed that the removal of crystal violate decrease with increase of temperature hence adsorption of crystal violate is an exothermic process [17].

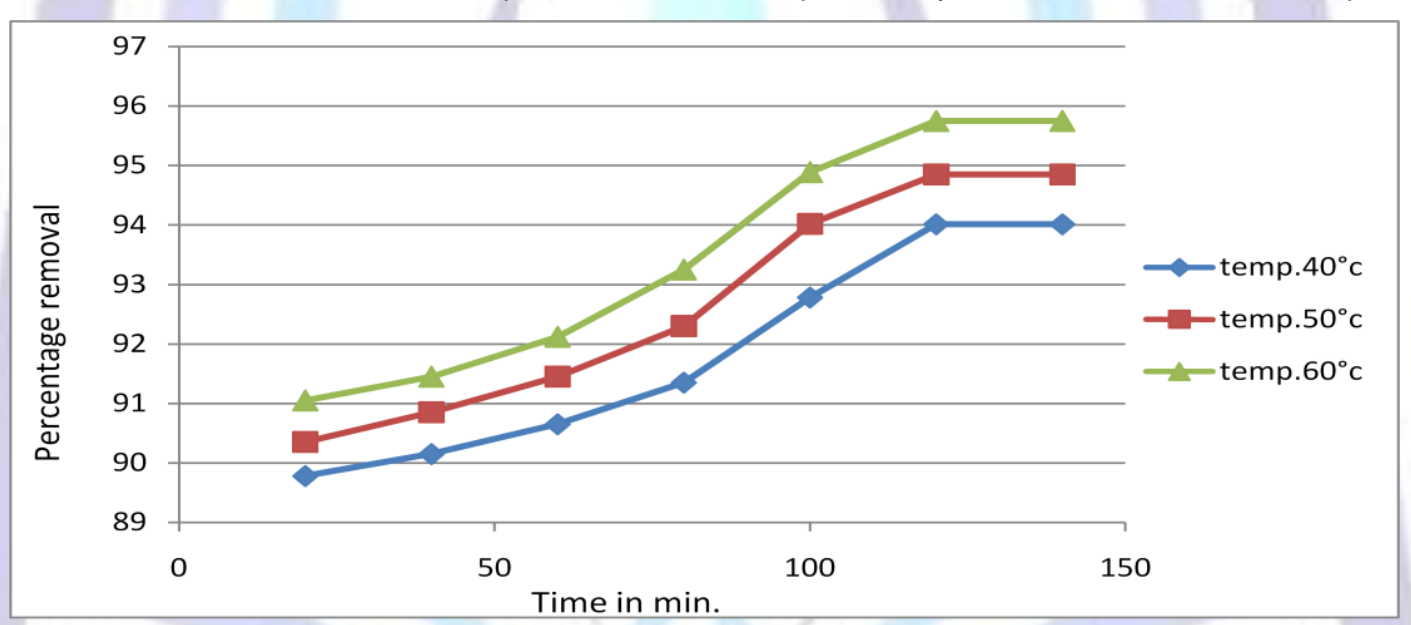

Fig.12: Effect of temp. On percentage removal of crystal violet dye, Initial dye concentration 60 ppm, contact time $120 \mathrm{~min}$. at $\mathrm{pH} 10$

\subsection{ADSORPTION KINETICS}

The kinetics of adsorption study is quite significant as it decides the residence time of adsorbate at the rate of adsorption process. The dye concentration and adsorbent dose are the important parameter because they determine capacity of adsorbent for a given initial concentration of dye solution. The study includes adsorption rate study .The kinetics of adsorption of crystal violate on PWCAC and CSAC mixture were analyzed using pseudo first order (Lagergren), Pseudo $2^{\text {nd }}$ order kinetic models. The conformity between experimental data and the model predicated values were expressed by Correlation coefficient $\left(r^{2}\right)$.A relatively high $r^{2}$ value indicate that the model successfully describes the kinetics of crystal violate adsorption. The dye removal from the solution is through the mechanism of adsorption.

\subsubsection{Pseudo first order equation}

The Pseudo first order (Lagergren) equation is generally expressed as

$\log (q e-q t)=\log q e-(K 1 / 2.303) t$

where qe and $\mathrm{q}_{\mathrm{t}}$ are the amount of dye adsorbed $(\mathrm{mg} / \mathrm{g})$ on PWCAC and CSAC mixture at equilibrium and at time't, respectively, $\mathrm{K}_{1}$ is a rate constant of pseudo first order adsorption ( $\left.\mathrm{min}^{-1}\right)$. The rate constant $\mathrm{K}_{1}$ and qe for first order equation are determined from the slope and intercept of the plot of log (qe-qt) vs. time respectively (fig.13) 


\section{ISSN 2321-807X}

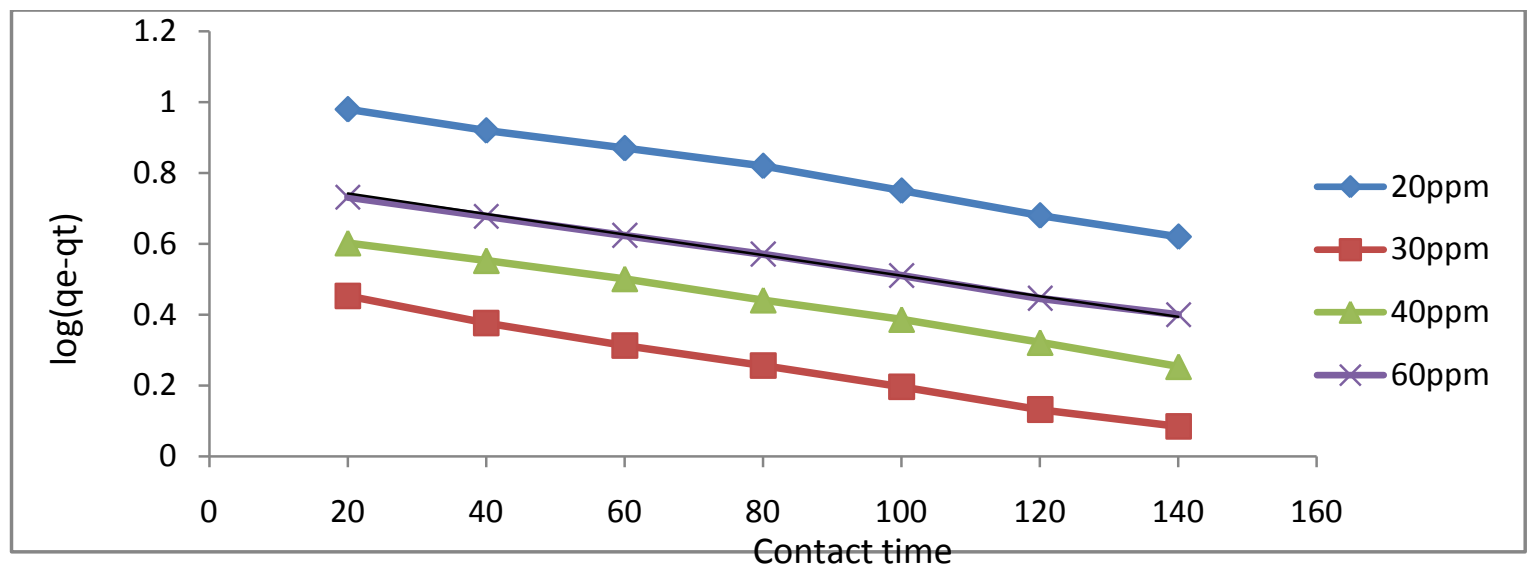

Fig.13: Lagergren 1st order plot for adsorption of crystal violate By PWCAC and CSAC mixture for different initial dye concentration adsorbent dose $4 \mathrm{gm} / \mathrm{L}$ and $\mathrm{pH} 10$.

The linear relationship of the plot for $20,30,40$ and $60 \mathrm{mg} / \mathrm{L}$ dye concentration indicates the validity of equation. The corelation coefficient $r^{2}$ of the first order equation is $(0.967$ to 0.99$)$ the value of qe calculated from first order kinetics plots were not same as compared to experimental (Table1).It shows that the rate constant $\mathrm{K}_{1}$ is not the same with increase in initial dye concentration and adsorbent dose. It shows the inapplicability of Lagergren equation to describe the kinetics of crystal violate.

\subsubsection{The pseudo second order equation}

The kinetic data were further analyzed using Pseudo second order kinetic model which is

expressed as (18)

$t / q t=1 / K 2 q e+t / q e$ and $h=K_{2} q e^{2}$

Here $\mathrm{K}_{2}$ is rate constant of second order

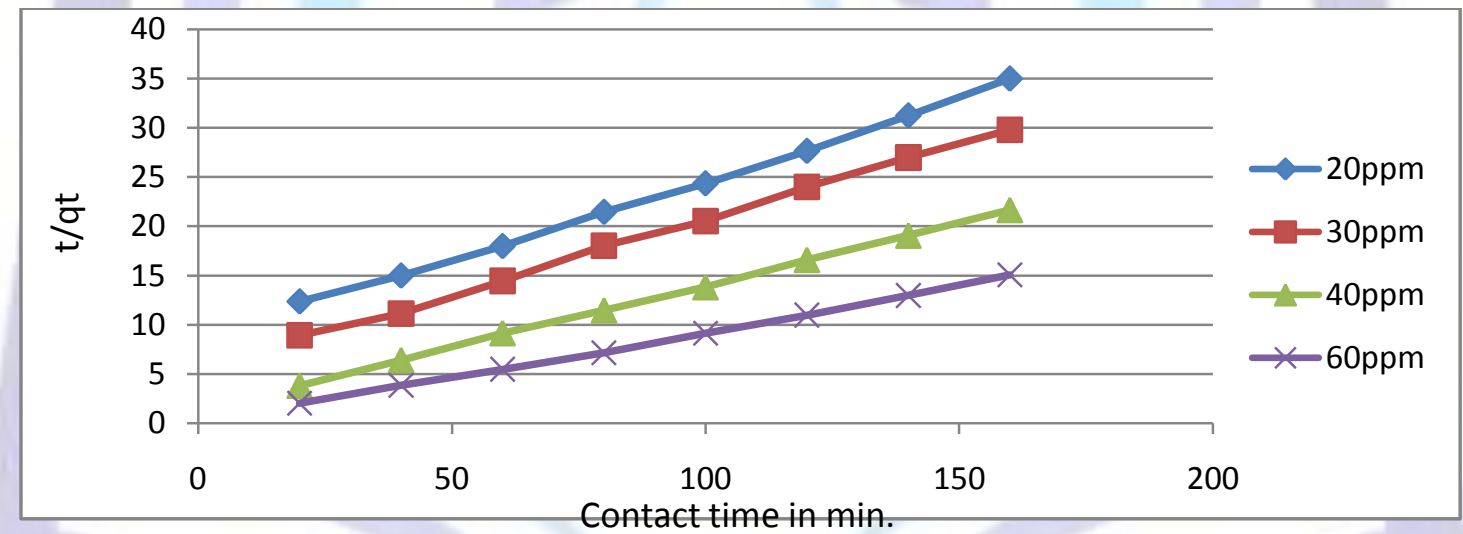

Fig.14: Plot of pseudo 2nd order model at different initial dye concentration forcrystal violate, adsorbent dose $4 \mathrm{~g} / \mathrm{L}$ and $\mathrm{pH} 10$.

The plot of t/qt vs.(fig.14) of the above equation gives linear relationship from which qe and $\mathrm{K}_{2}$ can be determine from the slope and intercept of the plot respectively. The linear plot of $t / q t$ vs. $t$ show a good agreement of experimental data with second order kinetic model for different initial dye concentration 20,30, 40,60 mg/L and for different adsorbent dose. The calculated qe, $\mathrm{K}_{2}$ and corresponding linear regression correlations coefficients $r^{2}$ value are sumrised in a table(2) .The values are greater than 0.999 (Table 1) which indicate the applicability of kinetic equation and Pseudo second order nature of adsorption process of crystal violate on PWCACand CSAC mixture. The qe value increases' with increase in initial dye concentration and adsorbent dose. The calculated qe values are agreed well with the experimental values. 
Table No1. Comparison of Adsorption rate constant, Calculated and experimental qe values for different initial dye and adsorbent dose for different kinetic model.

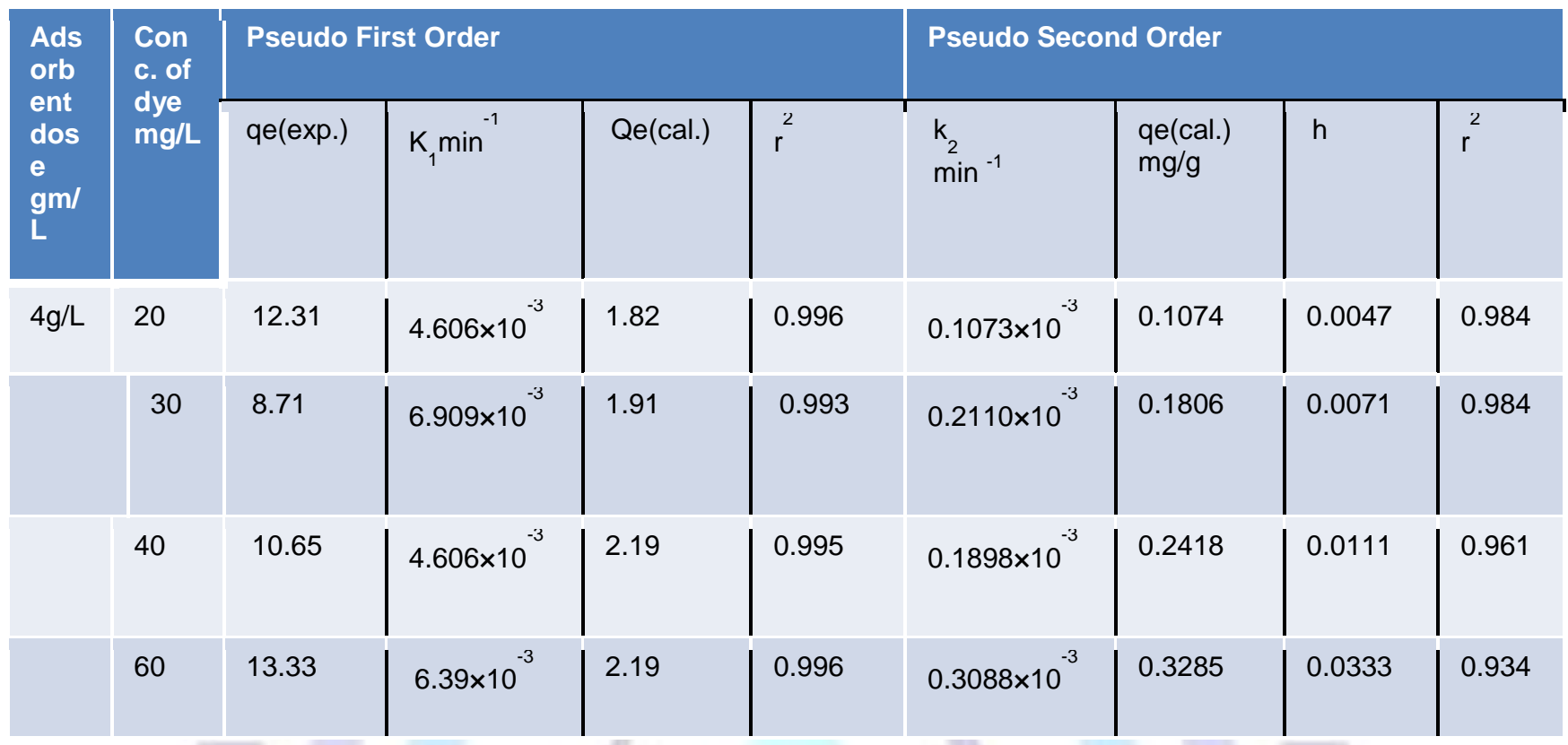

\subsection{ADSORPTION KINETICS}

The distribution of the dye between the liquid phase and the adsorbent is a measure of the position of equilibrium in adsorption process and can be generally expressed in Freundlich and Langmuir isotherm.

\subsubsection{Freundlich isotherms}

The linear plot of log qe vs. log Ce (Fig.15) confirms the applicability of the model. The logarithmic form of Freundlich isotherms equation is (20)

Log $q e=\log \mathrm{kf}+1 / \mathrm{n} \log \mathrm{Ce}$.

Where qe is the amount of dye adsorbed per unit mass of the adsorbent $(\mathrm{mg} / \mathrm{gm})$.Ce is the equilibrium concentration of the dye $(\mathrm{mg} / \mathrm{L})$, the $\mathrm{k}_{\mathrm{f}}$ represent quantity of dye adsorbed in $\mathrm{mg} / \mathrm{gm}$ for unit concentration of dye and $1 / \mathrm{n}$ is is measure of adsorption density. There is a linear plot of $\log q e \mathrm{vs}$. $\log \mathrm{Ce}$ for $10,20,30$ and $40 \mathrm{mg} / \mathrm{L}$ dye concentration. The $\mathrm{k}_{\mathrm{f}}$ and $\mathrm{n}$ values were calculated. From the intercept and slope of the plot are presented in table 2.The correlation coefficient of the graphs are $r^{2}<0.9949$ indicate the inapplicability of isotherms.

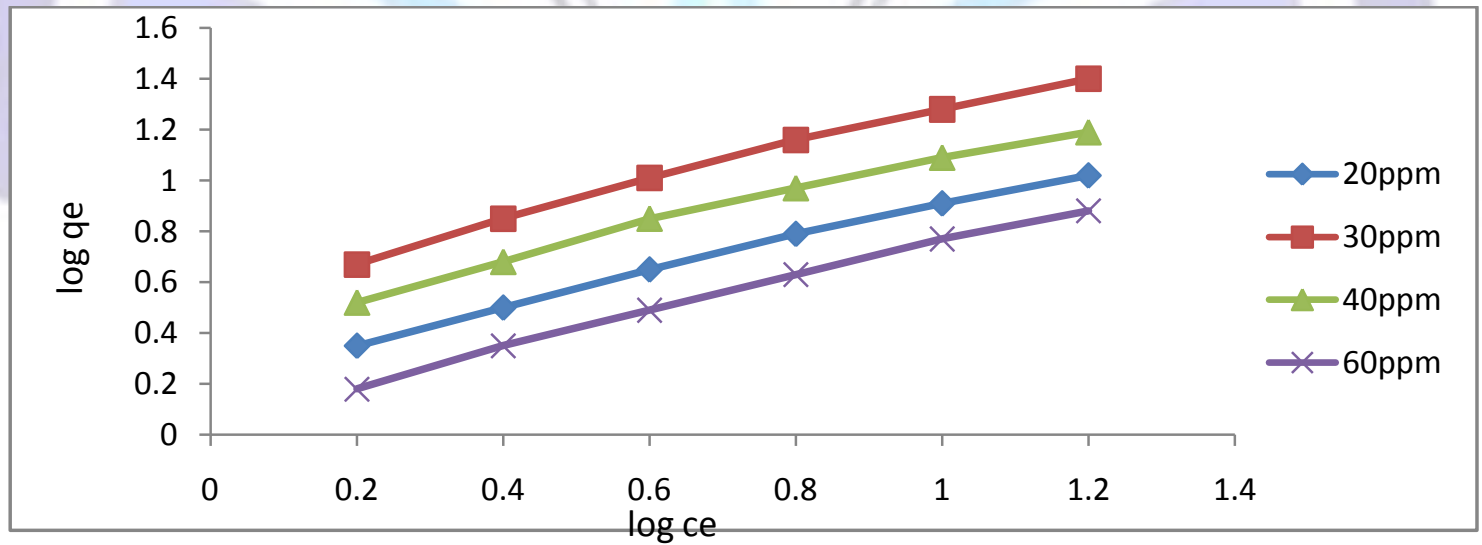

Fig.15: Freundlich plot for adsorption of crystal violateby PWCAC and CSAC mixture, pH 10 and adsorption dose $4 \mathrm{~g} / \mathrm{L}$

\subsubsection{Langmuir isotherms}

Langmuir isotherms is represented by the following equation ]21]

$\mathrm{Ce} / \mathrm{qe}=1 / \mathrm{ab}+\mathrm{ce} / \mathrm{b}$. . .4

Where $\mathrm{Ce}$ is the concentration of the dye solution $(\mathrm{mg} / \mathrm{gm})$ at equilibrium. The constant 'a' signifies the the adsorption capacity $(\mathrm{mg} / \mathrm{gm})$ and ' $b$ ' is related to energy and adsorption $(\mathrm{L} / \mathrm{mg})$. The linear plot of Ce/qe vs. Ce shows that the 
adsorption fallows the Langmuir isotherms (Fig.12). The values of ' $a$, and' $b$ 'were calculated from the slope and intercept of the linear plots and represented in Table 3.The applicability of the Langmuir isotherms suggest the monolayer coverage of the dye on the surface of PWCACand CSAC mixture. The essentials characteristics of the Langmuir isotherms can be expressed by the dimensional constant called equilibrium parameter $\mathrm{RL}$ and defined by the equation[22-23].

$\mathrm{RL}=1 /(1+\mathrm{bci})$. .5

Where $b$ is the Langmuir constant and $C_{i}$ is the initial dye concentration (mg/l).According to the values of the $R L$, The isotherms shape may be interpreted as if $R L$ is $>1$, unfavorable. $R L=1$ Linear, $R L>0$ favorable and $R L=0$ irreversible adsorption [24-25]. The results given in Table3 shows that the adsorption of crystal violate on PWCAC and CSAC mixture is favorable.

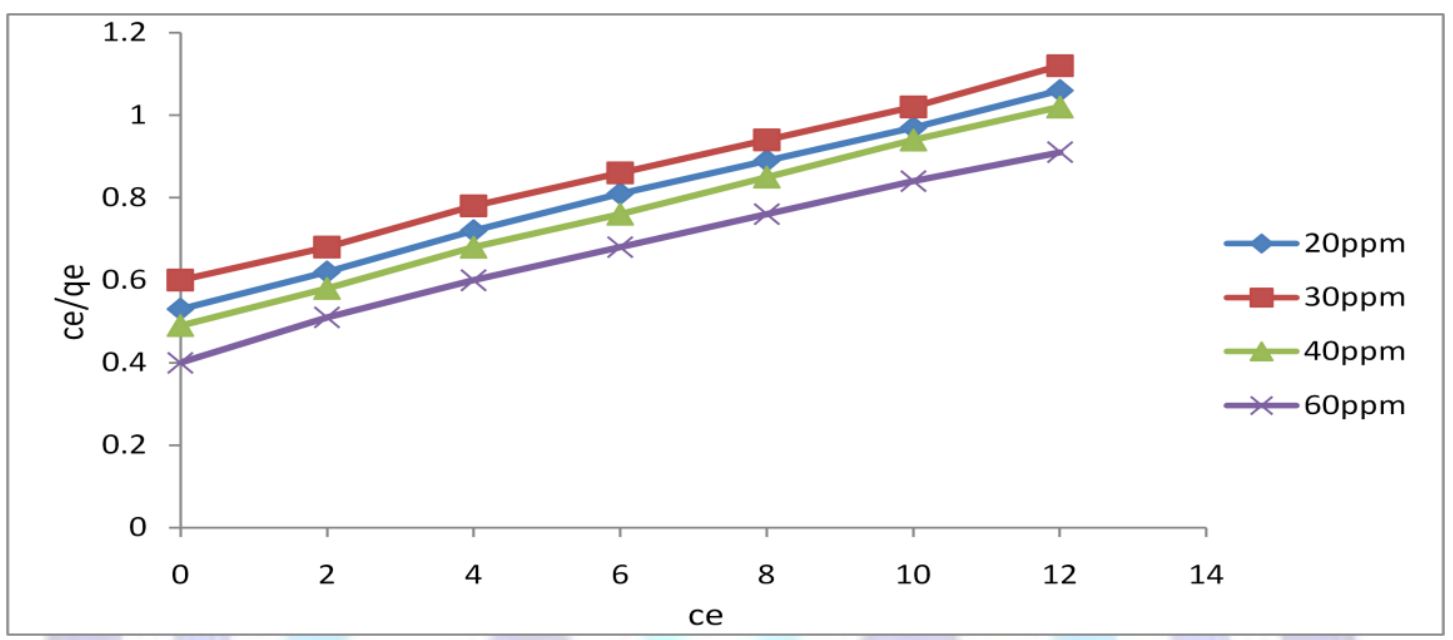

Fig.16: Langmuir plot for adsorption of crystal violate by PWCAC and CSAC mixture pH10 and adsorbent dose $4 \mathrm{~g} / \mathrm{L}$

Table 2 Freundlich and Langmuir coefficient for adsorption of crystal violate on PWCAC and CSAC mixture for different dye concentration and adsorbent dose from $4 \mathrm{gm} / \mathrm{L}$ and $\mathrm{pH} 10$

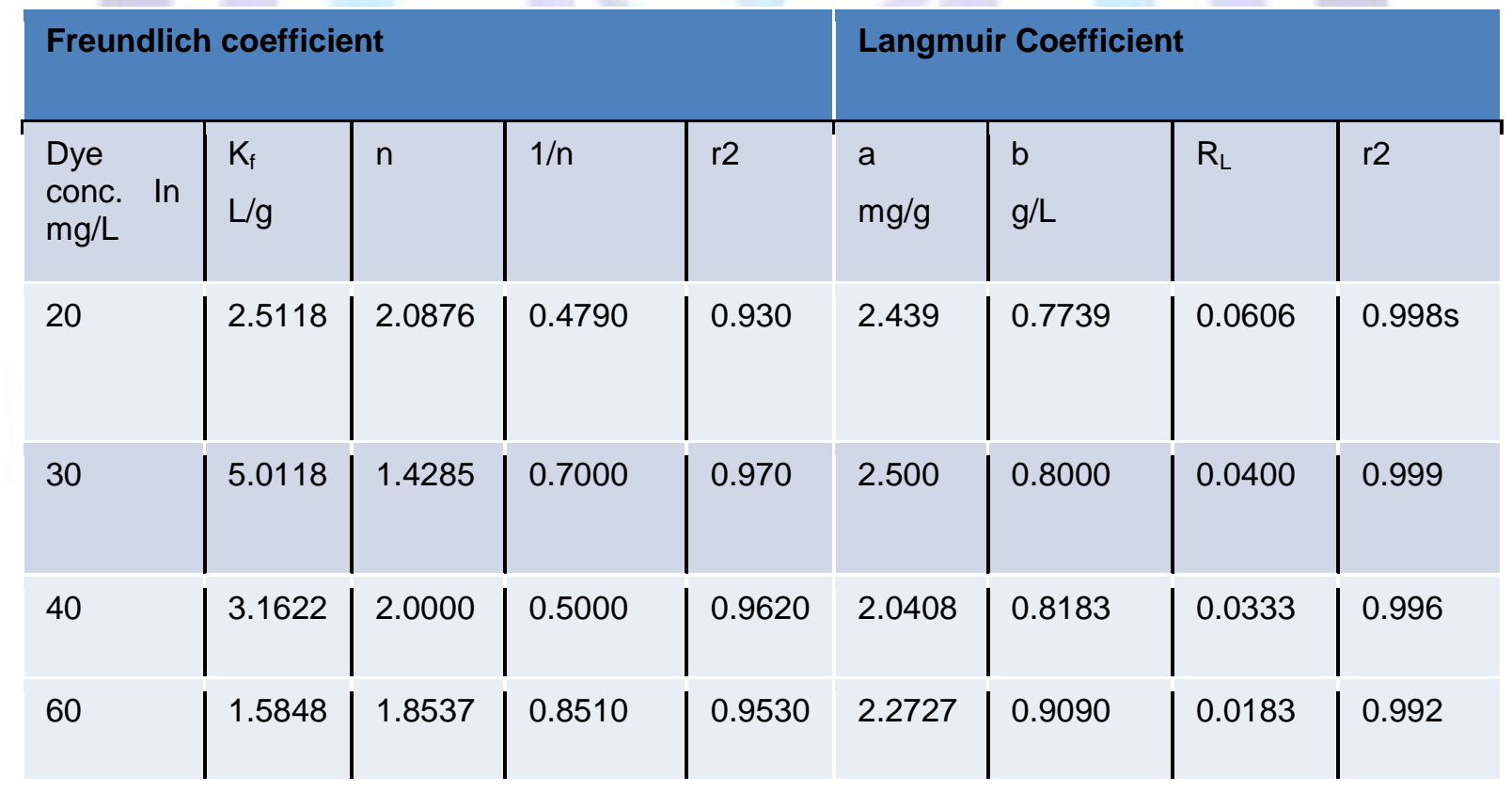

\section{CONCLUSIONS}

[1] The adsorption study indicates that, the agro based material palm wood cellulose activated carbon and coconut shell activated carbon can be used as an effective adsorbent for the removal of crystal violate dye from aqueous solution.

[2] The adsorption experiments were conducted in a batch mode for the concentration range 20 to $60 \mathrm{mg} / \mathrm{L}$ at $\mathrm{pH} 10$ and for an adsorbent dose 0.02 to $4 \mathrm{~g} / \mathrm{L}$ and up to contact time $120 \mathrm{~min}$.

[3] The equilibrium was achieved in $120 \mathrm{~min}$ and maximum adsorption capacities were observed at pH10 and adsorbent dose $4 \mathrm{~g} / \mathrm{L}$. 


\section{ISSN 2321-807X}

[4] The amount of dye uptake (mg/gm) was found to be increases with increase in contact time, initial dye concentration and it decreases with an increase in adsorbent dose.

[5] The adsorption rate was found to confirm to pseudo second order kinetics with good co relation.

[6] The equilibrium data fit very well in Langmuir isotherms equation. It confirms the capacity of Crystal violate dye on to PWCAC and CSAC with a monolayer adsorption capacity.

[7] The dimensionless separation factor (RL) called equilibrium parameter showed that PWCAC and CSAC could be used for the removal of Crystal violate from aqueous solution.

\section{ACKNOWLEDGEMENT}

The authors are thankful to the Principal G.T.P College, Nandurbar for providing necessary laboratory facilities .The authors would like to acknowledge Director, SICART, sand VALLABH VIDYANAGAR for FTIR, SEM, and XRD analysis. The authors are also grateful to the Principal JES'S Arts, Commerce, and Science College, Nandurbar for their co-operation and inspirations.

\section{REFERENCES}

[1] Fan,L, Zhou,Y.,Yang,W.,Chen,G.,Yang,Y., Dyes and pigment, 76(2008), 440

[2] Mckym,G.,Portar,J.F., Prasad,G.R., The removal of dyes colores from aqueous solution by adsorption on low cost material, water air soil pollution,114(1999),423-438.

[3] Kumar,K.V.,Subanandam.,Removal of basic dyes from its aqueous solution by adsorption process using rise husk adsorbent., Indian journal of chemical engineering., 13(2004), 1-46

[4] Dogan,M.,Alkne,M., The removal of methyl violet from aqueous solution by perlight.,Journal of colodial interface Science, 267(2003), 32-41.

[5] Jadhav,D.N., Vanjara,A.K.,Adsorption kinetic study : Removal of dye stuff effluent using saw dust polimarised saw dust and saw dust carbon., Indian journal of chemical technology.,11(2004),42-50

[6] Robinson,T.,Chandran,B.,Nigam,P.,Water resources,36(2002)2824-2830

[7] Garge,R.M.,yang,C.,Zung,Y.Z.,Zun,J.,Harad Matter.,121(2005)245-250

[8] Alau,K.K.,Gimba,C.K.,kagbu,J.A.,Nale,B.Y.,preparation of activated carbon from Neem husk by chemical activation with $\mathrm{H}_{3} \mathrm{PO}_{4}, \mathrm{KOH}$, and $\mathrm{ZnCl}_{2}$, Archives of applied science Research,2(5)2010.451-455

[9] Tarcila,C.R.,Juliana,C.,P.carina,A.,denise,Adsorption of crystal violate dye from aqueos solution on to zeolite from coal fly and bottom ashes, The electronic j.chemistry,5(3)(2013),179-191

[10] Devarly,P.,Kartika,Y.,Indraswati,N.,Ismadji,S.,Activated carbon from jackfruit peel waste by $\mathrm{H}_{3} \mathrm{PO}_{4}$ chemical activation,pore structure and surface chemistry characterization ,chem...Eng.Journal140,(2008),32-42

[11] Sonawane,G.H.,Shrivastava,V.S.,Kinetics of declourization of malachite green from aqueous medium by maize carbon agricultural solid waste,desalination,250(2009),94-105

[12] Tabrez Khan,A., Sangeeta Sharma and Imran ali,adsorption of Rhodamine B dye from aqueous solution on to acid activated mango leaf powder:Equilibrium,kinetic and thermodynamic studies,J.of toxicology and environmental health science,3(10)(20110),286-297

[13] Hema,M.,Arivoli,S.,comparative study on the adsorption kinetics and thermodynamics of dyes on to acid activated low cost carbon, International journal of physical sciences,2(1), (2007)10-17

[14] Rajeev Jain,Megha Mathur and Shalini sikarwar, Removal of indigocarmine from industrial effluents using low cost adsorbent,Journal of scientific and Industrial research,65(2006),258-263)

[15] Sharma,Y.C.,Uma,S.N.,Gode,F.,adsorptive removal of a basic dye from water and waste water by activated carbon,J.of applied sciences in environmental sanitation,8(1)(2009),21-28

[16] Taha Elmorsi,M.,Equilibrium isotherms and kinetics studies of removal of methylene blue dye by adsorption on to miswak leaves as an natural adsorbent,Journal of environmental protection,2(2011),817-827

[17] Nevine kamalamina,Removal of reactive dye from aqueous solution by adsorption on to activated carbons prepared from sugarcane bagasse pith,Desalination,223(2008),152-161

[18] Shihari,V.,Ashiutosh das,Adsorption of phenol from aqueous media by an agro-waste based activated carbon,applied ecology and environmental research,7(1)(2009),13-23

[19] Patil,A.K., Vinod Shrivastava., Kinetics and Equilibrium studies on the adsorption of crystal violet dye using Subabul seed pods as an adsorbent, journal of applied chemical research ,6 (4) (2012), 24-36.

[20] Fuat Gnzel, Hasansaygili, Gulbahav, Akkaya Saysilyi, Filizkoyyncy,Decolouration of aqueous crystal violet solution by Nanoporous carbon: Equilibrium and Kinetic approach, Journal of industrial and Engennering Chemistry 1753(2013). 
[21] Jain,J.K., Shrivastava Neha, Removal of basic organic dyes from effluent water of dyeing and printing units using some bioadsorbent, International Journal of Scientific Research, 2(3) (2013), 20-23.

[22] Minakshi Sundaram,M., Shahul Hammit,K., Adsorption kinetics of crystal violet dye on commercial activated

[23] Etim,U.J.,Inam,E.,Umoral,S.A.,Eduek,U.M.,Dye removal from aqueous solution using coconut coir dust extract modified by polyvinyl alchoal: Novel Adsorbent, International journal of environment and bioenergy 5(2)(2013),62-79.

\section{Author biography}

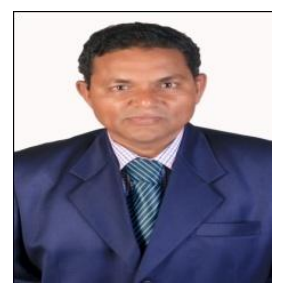

Full name : Wagh prakash bhila

Birth date :4.3.1963

Educational qualification: M.Sc.

Principle subject: physical chemistry

Designation: Associate: professor

Working place: Dept, of chemistry ,JEEs Arts ,Commerce and Science college Nandurbar, Maharashtra (India)

Affiliated university: North Maharashtra University Jalgaon ,Maharashtra(India)425412

Teaching experience: 27 years

Research experiences :4 years

Project completed :1

Research paper published: 03 